\title{
Prediction of the time constant of small-scale concentrated solar CHP plants
}

\author{
Roberto Tascioni ${ }^{\mathrm{a}, \mathrm{b}}$, Matteo Pirro $^{\mathrm{c}}$, Alessia Arteconia ${ }^{\mathrm{a}, \mathrm{d}, \mathrm{e}}$, Luca Del Zotto ${ }^{\mathrm{a}}$, Carlo M. Bartolini ${ }^{\mathrm{c}}$, Khamid Mahkamov ${ }^{\mathrm{f}}$, \\ Irina Mahkamova ${ }^{\mathrm{f}}$, Luisa F. Cabeza ${ }^{\mathrm{g}}$, Alvaro De Gracia ${ }^{\mathrm{g}}$, Piero Pili ${ }^{\mathrm{h}}$, André C. Mintsa ${ }^{\mathrm{i}}$, Toni Gimbernat ${ }^{\mathrm{j}}$, Teresa \\ Botargues $^{\mathrm{k}}$, David Mullen ${ }^{1}$, Luca Cioccolanti ${ }^{*}$ \\ ${ }^{a}$ Centro di Ricerca Energia Ambiente e Territorio (CREAT), Università eCampus, Via Isimbardi 10, 20060 Novedrate (CO), Italy \\ bDIAEE, Sapienza Università di Roma, via Eudossiana 18, Rome 00184, Italy \\ 'Società per il TRAsferimento TEcnologico e Guida all'Innovation Engineering, S.TRA.TE.G.I.E. srl, via Sandro Totti 1, Ancona \\ 60131, Italy \\ dDIISM, Università Politecnica delle Marche, Via Brecce Bianche 1, 60131 - Ancona, Italyì \\ 'Department of Mechanical Engineering, KU Leuven, Celestijnenlaan 300, 3001 Leuven, Belgium \\ ${ }_{\mathrm{f}}^{\mathrm{f} D e p a r t m e n t}$ Mechanical Engineering and Construction, Northumbria University, Newcastle upon Tyne NE1 8ST, UK, \\ ${ }^{g}$ GREiA Research Group, Universitat de Lleida, Pere de Cabrera s/n, Lleida 25001, Spain \\ hElianto S.R.L., Parco Scientifico e Tecnologico della Sardegna Località Piscina Manna - Edificio 1 Pula (CA) 09010, Italy, \\ ${ }^{i}$ Enogia S.A.S, 19 Avenue Paul héroult, Marseille 13015, France \\ ${ }^{j}$ E3G Ingegneria y energia, Av. Estudi General 7, Altell 5, Lleida 25001, Spain \\ kUSER FEEDBACK PROGRAM SL, Sant Jaume Apòstol 8, Almenar 25126, Spain \\ ${ }^{1}$ AAVID Thermacore Europe, 12 Wansbeck Business Park Ashington, Northumberland NE63 8QW, UK
}

\begin{abstract}
The operation of a power plant based on solar energy can vary significantly with time because of the intrinsic intermittency of the energy resource. Hence, a smart management is required to deal with the complex dynamic variations of the different subsystems. In order to do that, different control logics can be implemented but their effectiveness strictly depends on the temporal evolution of the parameters considered. For a given plant configuration, their exact estimation can be obtained through experimental tests during the commissioning of the plant. However, any change in the design parameters of the plant reflects in a different time constant, whose preliminary knowledge may be of support in tuning the control logic of the plant during the design stage. Therefore, based on the configuration of a small-scale concentrated solar combined heat and power plant as designed and built under the EU funded project Innova MicroSolar by several universities and companies, in this study a prediction of the time constant of several plant configurations with varying solar multiple and size of the storage tank is performed. By making use of the dynamic simulator previously developed by some of the authors, an estimation of such characteristic is assessed in case of potential redesign of the plant, providing also useful suggestions into the design of the control logic.
\end{abstract}

\section{Introduction}

An energy transition based on renewable technologies is required in order to meet the challenging targets set out by the Paris Agreement [1]. Among the different renewable sources, solar energy represents the most promising and clean energy for future power generation. In particular, the use of solar energy in decentralized energy systems (micro-Combined Heat and Power, $\mathrm{mCHP}$ ) is foreseen as a valuable alternative to substitute the thermal and electric power generation from fossil fuels. Due to the unpredictability of such renewable energy source, energy storage technologies are usefully adopted in these systems. Over the years, many researchers have paid their attention on the development of different storage technologies and in particular Thermal Energy Storage (TES) technologies (sensible or latent) [2]. In order to efficiently convert solar energy into generated power, Organic Rankine Cycle (ORC) systems are considered one of the most competitive at large scale [3]. Hence, many efforts have been put by academia and industry to achieve advancements with the final aim of making micro-solar CHP plants costcompetitive in the near future. Several concentrated solar ORC configurations have been designed and tested

* Corresponding author: luca.cioccolanti@uniecampus.it 
in the last decade. An example is the system here presented: a small-scale concentrated solar combined heat and power plant, developed within the Innova MicroSolar EU funded project [4]. In a previous work by some of the authors of the present paper [5], the annual performances of this novel micro concentrated solar ORC CHP system have been numerically evaluated, finding that proper control of the system was fundamental to optimize the operation of the different sub-systems with varying ambient conditions and user needs. In particular, as highlighted also by other authors [6], the thermal inertia of concentrated solar power plants plays a major role in their transient behaviour. An example of the influence of the thermal inertia in such systems is provided also in [7], where the combination of the activated thermal mass of the storage included in the plant and the smart control logic shows a relevant impact on the overall system performance. Hence, in order to properly design and optimize the control system and its logic, the dynamics of the plant need to be carefully investigated. In a previous work, Cioccolanti et al. [8] have developed a hardware-in-the-loop simulator to optimize the control algorithms and assess the best control strategy of a given configuration. this paper, instead, aims at quantifying the influence of some design parameters on the time-constant of the different subsystems of the micro solar CHP system under analysis by varying the size of some key components. The obtained results are expected to provide useful insights for the optimal design of the control of similar plants.

\section{Methods and models}

In this paragraph the methodology of the work and the main characteristics of the models are presented.

Starting from the configuration of the small-scale concentrated solar combined heat and power plant as designed and built under the EU funded project Innova MicroSolar [4], several design parameters of the plant are varied and the time constant of the different subsystems assessed with the final aim of supporting the future tuning of the control logic of similar systems.

The reference configuration of the plant consists of: (i) a $146 \mathrm{~m}^{2}$ solar field based on Linear Fresnel Reflectors (LFR) producing heat at temperatures in the range $250-280^{\circ} \mathrm{C}$; (ii) a $2 \mathrm{kWe} / 18 \mathrm{kWt}$ regenerative Organic Rankine Cycle (ORC) unit; (iii) a 3.8 tons of Phase Change Material (PCM) thermal storage tank equipped with reversible heat pipes; and (iv) a balance of plant (BOP) with a total length of $49 \mathrm{~m}$ pipes connecting all the different subsystems. This plant has been installed in the city of Almatret (Spain) coupled to a residential building and it is going to be tested in the forthcoming months. Further details about the plant can be found in [9]. Figure 1 shows a scheme of the plant under investigation.

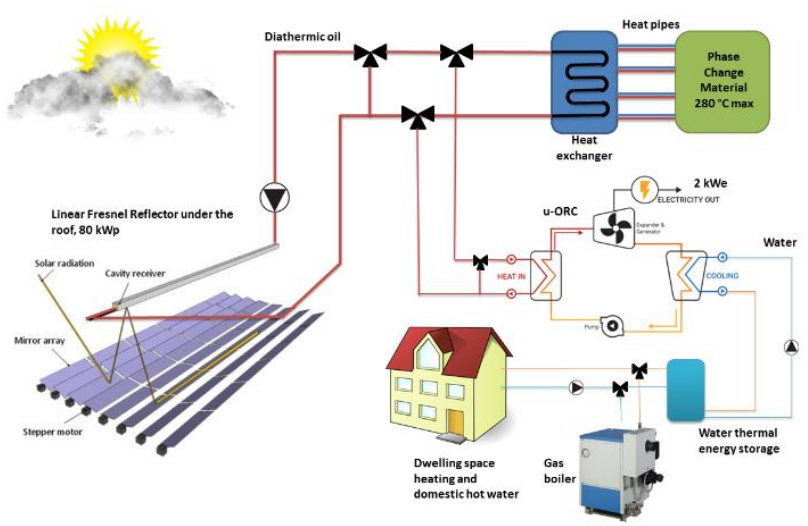

Fig. 1. Scheme of the Innova MicroSolar concept.

Depending on the solar radiation and the state of charge of the Latent Heat Thermal Energy Storage (LHTES), the plant works according to different Operation Modes $(\mathrm{OM})$ as summarised in Table 1. In particular, in OM1 the diathermic oil from the solar field, at temperature higher than $210^{\circ} \mathrm{C}$, flows directly to the ORC unit. When the collected power from the solar field exceeds the nominal power input to the ORC (about $28 \mathrm{kWt}$ ), instead, the oil supplies both the TES and the ORC unit (OM4). However, if the TES is fully charged, the LFR collector defocuses (OM-1). On the contrary, when the power produced by the solar field is low or zero and the average TES temperature is within an operating range close to the melting phase $\left(\mathrm{T}_{\mathrm{ORC}, \text { on }}=217^{\circ} \mathrm{C}\right.$ and $\mathrm{T}_{\mathrm{ORC}, \text { off }}$ $=215^{\circ} \mathrm{C}$ with hysteresis), the thermal energy of the TES can be used to run the ORC unit and assure its operation for a maximum of 4 hours with no sun. In particular, in OM5 only the PCM thermal energy storage supplies the ORC, while in OM6 both the LFR solar field and the TES supply the ORC unit.

Table 1. Operation Mode of the Innova Microsolar plant

\begin{tabular}{|c|c|c|}
\hline $\mathrm{OM}$ & $\begin{array}{l}\text { Connected } \\
\text { subsystems }\end{array}$ & Operating conditions \\
\hline-1 & $\begin{array}{c}\text { LFR (defocused) } \\
+ \text { ORC }\end{array}$ & oil flow rate $=0.22 \mathrm{~kg} / \mathrm{s}$ \\
\hline 0 & $\begin{array}{l}\text { LFR } \\
\text { recirculation }\end{array}$ & $\begin{array}{c}\text { if } \mathrm{P}_{\mathrm{LFR}, \text { out }}<15 \mathrm{~kW} \text { th and } \\
\mathrm{T}_{\mathrm{LFR}, \text { out }}<\mathrm{T}_{\mathrm{TES}, \mathrm{av}} \\
\text { oil flow rate }=1 \mathrm{~kg} / \mathrm{s} \\
\end{array}$ \\
\hline 1 & $\mathrm{LFR}+\mathrm{ORC}$ & $\begin{array}{c}\text { if } 15 \mathrm{~kW} \text { th }<P_{\text {LFR,out }}<26 \mathrm{~kW} \text { th, } \\
0.11 \mathrm{~kg} / \mathrm{s}<\text { oil flow rate }<0.22 \\
\mathrm{~kg} / \mathrm{s}\end{array}$ \\
\hline 2 & Plant off & if $P_{\text {LFR, out }}=0 \mathrm{~kW}_{\text {th }}$ \\
\hline 3 & LFR + LHTES & $\begin{array}{l}\text { if } P_{\text {LFR,out }}<15 \mathrm{~kW} \text { th, } \\
\mathrm{T}_{\text {LFR,out }}=\mathrm{T}_{\mathrm{TES}, \text { av }}+10^{\circ} \mathrm{C}\end{array}$ \\
\hline 4 & $\begin{array}{l}\text { LFR + LHTES } \\
\quad+\text { ORC }\end{array}$ & $\begin{array}{c}\text { if } P_{\text {LFR,out }}>26 \mathrm{~kW}_{\text {th }} \text { and } \\
\mathrm{T}_{\text {TES,av }}<280^{\circ} \mathrm{C} \text {, } \\
0.22 \mathrm{~kg} / \mathrm{s}<\text { oil flow rate }< \\
3 \mathrm{~kg} / \mathrm{s} \text { otherwise OM-1 }\end{array}$ \\
\hline 5 & LHTES + ORC & $\begin{array}{l}\text { if } P_{\text {LFR, out }}=0 \mathrm{~kW} \text { th, } \\
\text { oil flow rate }=3 \mathrm{~kg} / \mathrm{s}\end{array}$ \\
\hline 6 & $\begin{array}{c}\text { LFR + LHTES } \\
+ \text { ORC }\end{array}$ & $\begin{array}{l}\text { if } P_{\text {LFR,out }}<15 \mathrm{~kW} \text { th, } \\
\text { oil flow rate }=3 \mathrm{~kg} / \mathrm{s}\end{array}$ \\
\hline
\end{tabular}


All the subsystems are connected each other by proportional valves which allow the operation of the system in the different OM while the control strategy developed so far aims at maximizing the electricity generation using a deterministic approach.

The plant is modelled in MATLAB /Simulink [10] using MATLAB function blocks and, in order to take into account the transient operation of the real plant, dynamic models of some components have been included. More precisely, the receiver tube of the LFR system, the LHTES and the pipelines of the BOP have been represented with dynamic models, whilst the ORC unit by a quasi-steady state model. Indeed, the latter as a significant lower thermal inertia compared to the above subsystems.

As regarding the thermal power output from the solar field it can be calculated as in Eq. 1:

$$
P_{L F R, o u t}=A_{s f} D N I \cdot \cos (\theta) \cdot \eta_{o p t} \cdot \eta_{\text {rec }}
$$

where $A_{s f}$ is the net area of the primary collectors, DNI is the Direct Normal Irradiance, $\theta$ the incident angle obtained from the Solar Position Algorithm by National Renewable Energy Laboratory - NREL [11], $\eta_{\text {opt }}$ the optical efficiency of the LFR which depends on the Incident Angle Modifier and $\eta_{\text {rec }}$ the receiver efficiency calculated by applying the well-known Forristal model [12] for the evacuated tubes. With regard to $\eta_{\text {opt }}$, it is implemented in the model through a lookup table whose values have been assessed by a ray tracing analysis by the manufacturing company ELIANTO [13].

The LHTES has been represented by means of a lumped model according to the guidelines of the IEA Task 32 report on advanced storage concepts [14] where a detailed description is provided. The PCM is supposed isotropic and isothermal in each internal time-step and it consists of nitrate solar salt $\mathrm{KNO}_{3}(40 \mathrm{wt} \%) / \mathrm{NaNO}_{3}(60$ $\mathrm{wt} \%$ ), which has a melting temperature in the range 216$223{ }^{\circ} \mathrm{C}$. The use of heat pipes is included in the model in terms of maximum power exchanged with the oil (40 $\mathrm{kW}$ ) and a minimum temperature difference between the oil and the PCM (equal to $5{ }^{\circ} \mathrm{C}$ ). Hence, the temperature variation during a simulation time step of the LHTES is expressed as:

$$
\Delta T_{\text {LHTES }(t+1)}=\Delta T_{\text {LHTES (t) }} \cdot e^{[-\Delta t \text { int-timestep } f f]}
$$

where $\Delta T_{\text {LHTES }(t)}$ is the temperature difference between the heat pipe immersed in the PCM and the PCM itself at time step $t$, while $f$ depends on the convective Nusselt number of the PCM. An internal time step is chosen to increase the model accuracy especially during the physical discontinuities introduced at the beginning and the end of the phase change.

The tank is $1.93 \mathrm{~m}^{3}$ and its thermal losses calculated considering a thermal resistance of the storage of 0.4 $\mathrm{W} / \mathrm{m}^{2}$.

As regarding the pipelines of the BOP a one dimensional longitudinal model is included, thus taking into account the influence of their thermal inertia on the plant performance. Hence, a simplified advection equation is solved for each tube:

$$
\partial\left(\rho c_{p} T A\right) / \partial t+\partial\left(\rho u c_{p} T A\right) / \partial x=-P_{\text {exch }}
$$

where $\rho, c_{p}, T$ and $u$ are the density, the specific heat, the temperature and the axial velocity of the oil respectively, A the internal cross section area of the tube, and $\mathrm{P}_{\text {exch }}$ is the exchanged power between the fluid and the environment (positive for losses, negative for gain). The advection equation is solved using the finite difference method coded in MATLAB with the explicit first order upwind scheme. Moreover, the code vectorization in the longitudinal direction allows drastically reducing the computational efforts required by the code. More details of the pipelines model can be found in [15]. The same numerical scheme has been applied to make the Forristal model of the receiver tubes dynamic. In this case, only the thermal inertia of the diathermic oil has been considered while that of the metal parts and the glass tube neglected.

Eventually, the ORC unit is modelled considering a quasi-steady state operation. The electric power generated by the ORC is calculated as:

$$
P_{e l}=m_{f}\left[\eta_{m} \cdot \eta_{e l} \cdot \Delta h_{e}-\Delta h_{p} /\left(\eta_{m} \cdot \eta_{e l}\right)\right]
$$

in which $\Delta \mathrm{h}_{\mathrm{e}}$ and $\Delta \mathrm{h}_{\mathrm{p}}$ are the expander and pump enthalpy difference, $\eta_{\mathrm{m}}$ and $\eta_{\mathrm{el}}$ the mechanical and electrical efficiency assumed constant and equal to 0.9 for both the expander and the pump. The turbine isentropic efficiency varies with the operating conditions and its value is based on the experimental data provided by the manufacturer ENOGIA [16]. More precisely, in preliminary laboratory tests it reaches a maximum value of 0.43 with an expansion ratio of 8 . Regarding the pump, a gear pump is installed and despite its small dimensions the isentropic efficiency has been assumed constant and equal to 0.7 .

The thermal power output, instead, is assessed as:

$$
P_{\text {th }}=m_{c} \cdot c_{p, c} \cdot\left(T_{\text {out }}-T_{\text {in }}\right)
$$

where $m_{c}$ is the flow rate of the cooling water, $c_{p, c}$ its specific heat and $T_{\text {in }}$ and $T_{\text {out }}$ the inlet and outlet temperatures of the cooling water at the condenser.

Heat exchangers have been modelled according to the $\varepsilon$-NTU method, assuming constant the overall heat transfer coefficient since the exact characterization of the plate heat exchangers was out of the scope of this work. The thermodynamic state points and the organic fluid flow rate (design value of $0.21 \mathrm{~kg} / \mathrm{s}$ ) are obtained at each time step according to an iterative procedure to achieve a fixed overheating temperature difference at the evaporator. In Figure 2 the thermodynamic cycle is reported for two different inlet temperatures at the evaporator, namely $220{ }^{\circ} \mathrm{C}$, which corresponds to the nominal operating condition and $150{ }^{\circ} \mathrm{C}$ which represents a part load condition. As can be noticed, the sliding pressure control is applied to partialize the output power based on the inlet fluid temperature. The thermodynamic states 6-7 and 4-5 depict the organic fluid conditions before the evaporator entrance and after the turbine respectively (regeneration). 


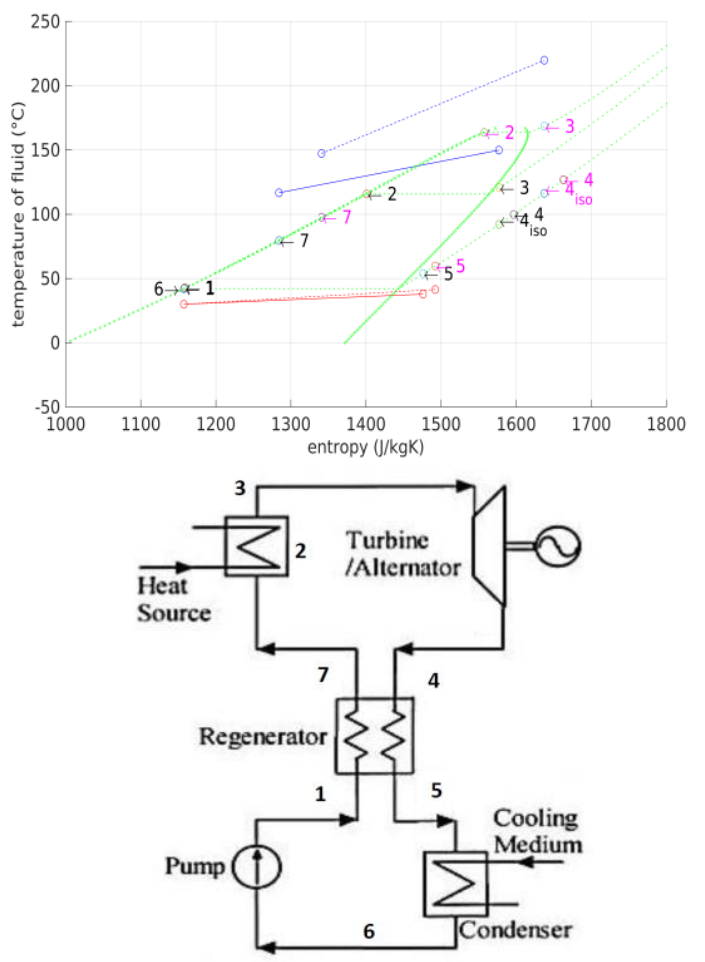

Fig. 2. T-s diagram and scheme of the Organic Rankine Cycle.

This study aims at assessing the time constant of a subsystem with its size. The final goal of the paper, indeed, is to provide useful info for the design of the control logic of small-scale concentrated solar plants having similar configurations. For the sake of the analysis, the time constant is determined as the time interval required by the output temperature from a sub-system to reach the $63 \%$ of its steady state value under a temperature step function. Unlike the storage system and the pipelines where a sharp temperature front at the inlet is applied, the LFR is subjected to a step DNI increment and decrement.

Furthermore, additional tests are carried out to evaluate in the worst scenario, namely at the nominal DNI and with the ORC and the LHTES sub-systems disconnected, the minimum time required to reach the maximum permitted temperature of the plant before the LFR sub-system starts its defocusing.

\section{Results and discussion}

In this section the investigation of some design parameters such as the area of the solar field, the size of the storage tank and the length of the pipeline of the BOP on the time constant is presented. For the purpose of comparison, the default design features of the Innova MicroSolar plant have been taken as reference (base scenario). In Table 2 the considered values of the parameters are reported: a technically feasible lower and higher value of the design value is assumed in order to look for possible trends in their relationship with the related time constant. The parameters are varied one by one in the dynamic simulation model, while the others are maintained fixed as in the base scenario.
Table 2. Design parameters scenarios used in the sensitivity analysis.

\begin{tabular}{|c|c|c|c|}
\hline Scenario & $\begin{array}{c}\text { Solar Field } \\
\left(\mathrm{m}^{2}\right)\end{array}$ & $\begin{array}{c}\text { LHTES } \\
\text { (tons) }\end{array}$ & $\begin{array}{c}\text { Length of BOP } \\
(\mathrm{m})\end{array}$ \\
\hline base & 146 & 3.8 & 30 (in OM1) \\
\hline 1 & 73 & 3.8 & 25 (in OM0) \\
\hline 2 & 219 & 3.8 & 25 (in OM0) \\
\hline 3 & 146 & 1.9 & 30 (in OM1) \\
\hline 5 & 146 & 5.7 & 30 (in OM1) \\
\hline 6 & 146 & 3.8 & 21 (in OM1) \\
\hline 5 & 146 & 3.8 & 39 (in OM1) \\
\hline
\end{tabular}

Firstly, the dynamics of the LFR has been investigated by assessing the thermal response time of the collector. Based on the specifications defined by ASHRAE 93-2003 [17] test standard and according to [18], the time constant, $\tau_{\mathrm{LFR}}$, of the receiver tube (overall length equal to $39 \mathrm{~m}$ ) is determined using either a step input of solar energy when the collector is focused (heating) or a withdrawal of solar energy while it is defocused (cooling). More precisely, accordingly to the ASHRAE guidelines the oil mass flow rate in the LFR solar field is fixed to $3 \mathrm{~kg} / \mathrm{s}$ considering a wind speed of $3.3 \mathrm{~m} / \mathrm{s}$ and ambient temperature. Hence, firstly the DNI is increased up to $900 \mathrm{~W} / \mathrm{m}^{2}$ and the outlet temperature from the receiver tube observed, as shown in Figure 3. In particular, the LFR heats up the oil and takes $28 \mathrm{~s}$ to reach the $63 \%$ of the asymptotic temperature difference between the outlet and the inlet. Then, once the LFR has achieved the steady state conditions at nominal power input, the LFR is fully defocused (DNI equal to $0 \mathrm{~W} / \mathrm{m}^{2}$ ) and in this way the response of the receiver tube during its cooling evaluated. Also in this second test the time

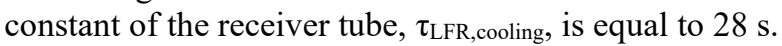

From the control system perspective, it is important to know for safety reasons also the time interval needed to reach the maximum permitted temperature of the oil $\left(320^{\circ} \mathrm{C}\right)$ in the solar field before the LFR defocusing phase (OM-1). In the worst scenario, namely when the oil recirculates only in the LFR loop (total length equal to $64 \mathrm{~m}$ including both the receiver tube of the LFR and the pipelines), and the DNI is equal to $900 \mathrm{~W} / \mathrm{m}^{2}$ (OM0), the warm up time corresponds to about $1300 \mathrm{~s}$. 

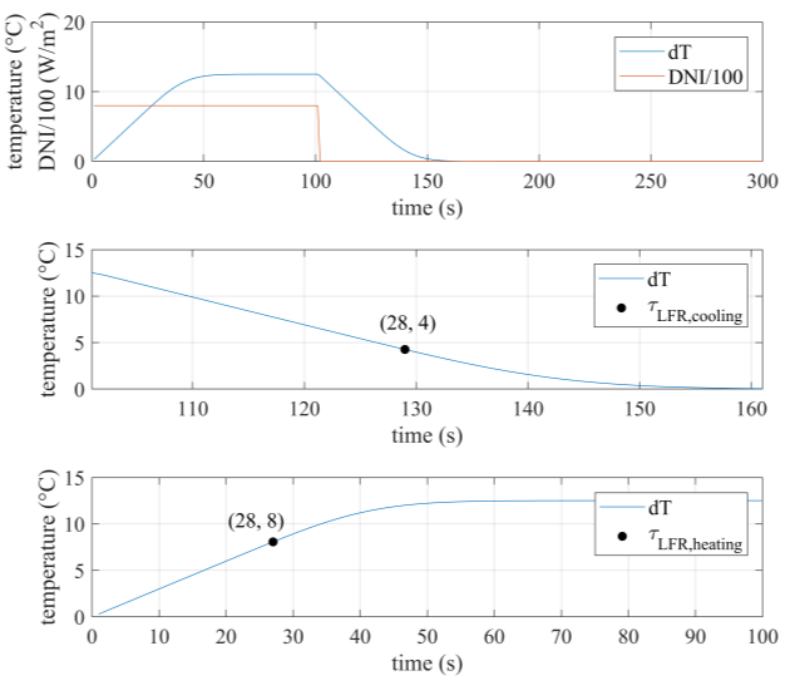

Fig. 3. Time characteristics of the receiver tube in the base scenario and the related temperature difference.

Hence, the results obtained for the base scenario configuration have been compared with those of scenarios 1 and 2. In particular, the LFR exhibits a warm up time of $1808 \mathrm{~s}$ and $1131 \mathrm{~s}$ in case of $73 \mathrm{~m}^{2}$ and 219 $\mathrm{m}^{2}$ area which correspond to overall lengths of the LFR loop in OM0 equal to $44.5 \mathrm{~m}$ and $83.5 \mathrm{~m}$ respectively because of the modification of the receiver length.

In order to appreciate the dynamics of different LHTES capacities, the time constant of such subsystem is assessed during its heating up, considering a fixed oil flow rate equal to $1 \mathrm{~kg} / \mathrm{s}$ and a temperature difference between the inlet oil and the LHTES equal to $30{ }^{\circ} \mathrm{C}$. Indeed, from a yearly simulation it can be notice an average temperature difference of about $20{ }^{\circ} \mathrm{C}$ during the working conditions, but it often peaks up to $30{ }^{\circ} \mathrm{C}$ (corresponding to the heat pipes limit). Thus, to cover a broader operation range, $30{ }^{\circ} \mathrm{C}$ seems to be the best choice for our evaluations. In this test, scenarios 3 and 4 are compared with the base scenario.

Figures 4 shows that decreasing the LHTES capacity to 1.9 tons both the time constant during the heating up $\tau_{\mathrm{TES}, \text { sensible }}$ and the time constant during the melting phase $\tau_{\mathrm{TES}, \text { latent }}$ reduce to 68 and $67 \mathrm{mins}$ respectively which correspond to half of that of the base scenario as expected. Conversely, an increase in the LHTES capacity to 5.7 tons (scenario 4 ) would lead to $\tau_{\text {TES,sensible }}$ and $\tau_{\text {TES,latent }}$ equal to 205 and 201 mins respectively. It is worth to noticing that even though the time constants during the heating and the melting phases are similar the LHTES has a higher heat transfer rate in the latter conditions and, as a consequence the storage exchanges higher thermal power during the phase change. More precisely, it exchanges $18 \mathrm{~kW}_{\text {th }}$ in sensible heat conditions (Figure 4a), while it works at $40 \mathrm{~kW}_{\text {th }}$ in latent conditions (Figure 4b). Hence, the longer time needed to reach the steady state conditions during the melting phase is compensated by the higher heat transfer rate. For the sake of clarity, it is important to specify that the trends in Figure $4 \mathrm{~b}$ are obtained considering a fixed temperature difference between the PCM and the oil of $30^{\circ} \mathrm{C}$ thus artificially extending the melting phase temperature range.

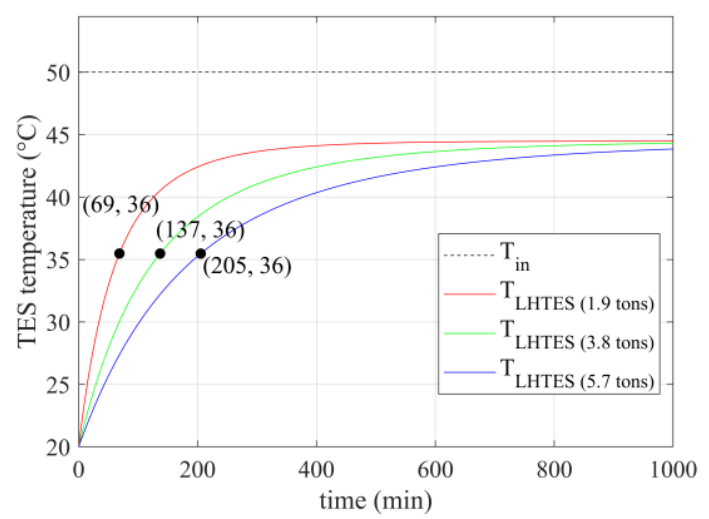

a)

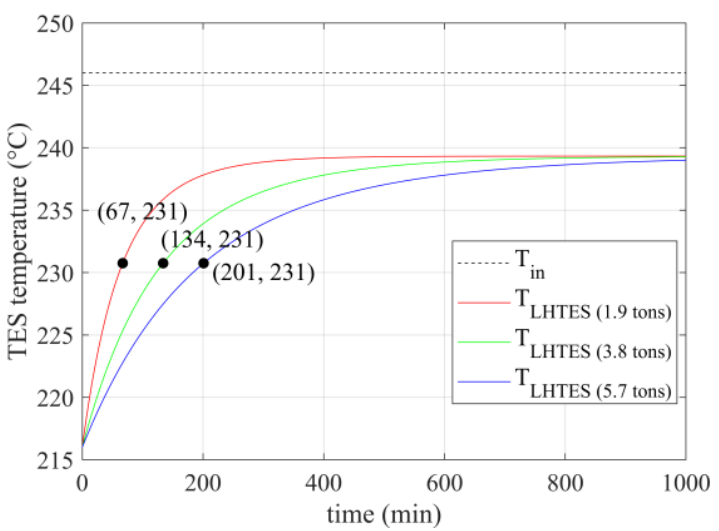

b)

Fig. 4. Time constant variation respect to the dimension of the LHTES storage: a) $\tau_{\mathrm{TES} \text {,sensible; }}$ b) $\tau_{\mathrm{TES} \text {,latent. }}$

Eventually, the dynamics of the pipelines of the BOP has been assessed considering the system operating in OM1 (the LFR system supplies the ORC unit only). In the base scenario this corresponds to a length of the BOP equal to $30 \mathrm{~m}$, while in scenarios 5 and 6 this length has been varied to $21 \mathrm{~m}$ and $39 \mathrm{~m}$ respectively.

In Figure 5 the results of the sensitivity analysis varying the length of the BOP are shown. As it can be clearly noticed for a given inlet temperature (i.e. $250{ }^{\circ} \mathrm{C}$ ) and oil flow rate (i.e. $0.22 \mathrm{~kg} / \mathrm{s}$ which corresponds to the nominal flow rate of the oil in the evaporator of the ORC unit), the oil takes more time prior to rise in temperature if the length of the BOP is increased. Specifically, more than 3 minutes are needed to achieve a steady state temperature in case of a length of the BOP of about 69 $\mathrm{m}$ and a slightly higher delay occurs for $78 \mathrm{~m}$. As regards the time constant, the overall time delay to reach the $63 \%$ of the peak value accounts to $2.8 \mathrm{mins}, 2.5$ mins and 3.08 mins for the base scenario, scenario 5 and 6 respectively. 


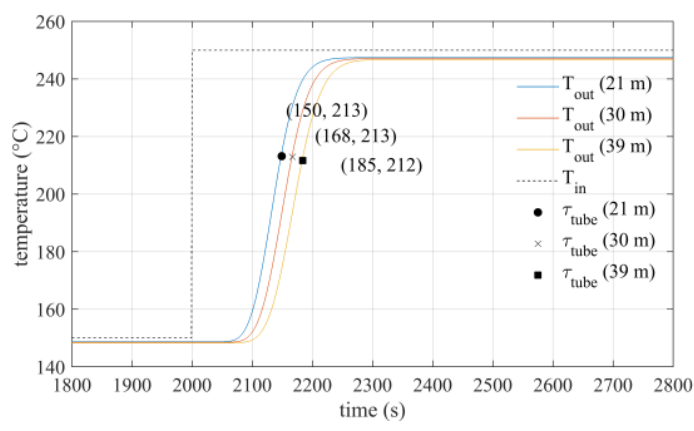

Fig. 5. Time constant variation according to the length of pipeline of BOP.

On the basis of the obtained results, the receiver tube has the lowest time constant while the pipelines have a time constant which strictly depends on the operation mode and, in case of OM1, is about 5-6 times more than that of the solar field. As expected, the LHTES has the highest time constants and their values provide also useful information about the maximum capacity that the storage should have with respect to the solar field area.

From the control point of view, the very slow dynamics of the overall system highlights the limited effectiveness of the control algorithms aimed at optimizing its response times. As a consequence, it is more useful to provide intelligent supervision techniques that can optimize the efficiency of the system by acting on the switch between the different OM, knowing the thermal inertia of each subsystem.

\section{Conclusions}

In this paper the effects of varying some design parameters of a micro-scale concentrated solar combined heat and power plant as designed and built under the EU funded project Innova MicroSolar on the time constants of the main subsystems have been investigated. The objective is to provide useful hints for the design and optimization of the control logic in case of different plant configurations. Therefore, a sensitivity analysis of the influence of solar field area, length of the pipeline extension (BOP) and size of the storage tank has been performed. The results show a greater influence of the plant piping length rather than the receiver length on the system inertia. Furthermore, the most relevant impact on the time constant value is due to the thermal energy storage size. Therefore, the time constants of the LHTES at different conditions (heating up and melting phases) need to be carefully considered at the time of tuning the control algorithms of the integrated plant, in order to take into account the slow dynamics of the system in the control strategies.

This study is a part of the Innova MicroSolar Project, funded in the framework of the European Union's Horizon 2020 Research and Innovation Programme (grant agreement No 723596).

\section{References}

1. REN21, RENEWABLES 2017 GLOBAL STATUS REPORT (2017)

2. U. Pelay, L. Luo, Y. Fan, D. Stitou, and M. Rood, Renew. Sustain. Energy Rev. (2017)

3. I. M. Aboelwafa, O; Fateen, S.E.K.; Soliman, A.; Ismail, Renew. Sustain. Energy Rev. 82, 868 (2018)

4. Innova-Microsolar, Http://InnovaMicrosolar.Eu/ (n.d.)

5. L. Cioccolanti, R. Tascioni, and A. Arteconi, Appl. Energy 221, 464 (2018)

6. M. Chafie, M. F. Ben Aissa, S. Bouadila, M. Balghouthi, A. Farhat, and A. Guizani, Appl. Therm. Eng. (2016)

7. R. Tascioni, A. Arteconi, L. Del Zotto, and L. Cioccolanti, Energies (2020)

8. L. Cioccolanti, R. Tascioni, M. Pirro, and A. Arteconi, Energy Convers. Manag. X 8, (2020)

9. K. Mahkamov, P. Pili, R. Manca, A. Leroux, A. C. Mintsa, K. Lynn, D. Mullen, E. Halimic, S. C. Costa, C. Bartolini, M. Pirro, L. F. Cabeza, A. D. G. Cuesto, M. Kenisarin, and I. Makhkamova, in Am. Soc. Mech. Eng. Power Div. POWER (2018)

10. Simulink, Simul. Model. Des. (n.d.)

11. NREL, Natl. Renew. Energy Lab. (n.d.)

12. R. Forristall, Heat Transfer Analysis and Modeling of a Parabolic Trough Solar Receiver Implemented in Engineering Equation Solver (2003)

13. Elianto, Conc. Sol. Power (n.d.)

14. P. Gantenbein, D. Jaenig, H. Kerskes, and M. Van Essen, (2008)

15. R. Tascioni, L. Cioccolanti, L. Del Zotto, and E. Habib, Energies (2020)

16. ENOGIA, Small Turbine ORC Co. (n.d.)

17. ASHRAE, Stand. 93-2010 (RA 2014) -Methods Test. to Determ. Therm. Perform. Sol. Collect. (ANSI Approv. (n.d.)

18. H. J. Hou, Z. F. Wang, R. Z. Wang, and P. M. Wang, Renew. Energy (2005) 